\title{
Structural Brain Alterations in Community Dwelling Individuals with Chronic Joint Pain
}

M. de Kruijf, D. Bos, F.J.P.M. Huygen, (DW.J. Niessen, H. Tiemeier, (D)A. Hofman, A.G. Uitterlinden, (D)M.W. Vernooij, (D)M.A. Ikram, and J.B.J. van Meurs

\begin{abstract}
BACKGROUND AND PURPOSE: Central sensitization in chronic pain involves structural brain changes that influence vulnerability to pain. Identifying brain regions involved in pain processing and sensitization can provide more insight into chronic pain. This study examines structural brain changes in chronic pain and experimental pain in a large population-based study.
\end{abstract}

MATERIALS AND METHODS: For 3892 participants in the Rotterdam study, global and regional MR imaging brain volumes were automatically segmented and quantified. Chronic joint pain was defined as pain for more than half of all days during the past 6 weeks. Heat pain thresholds were measured in a subset of 1538 individuals. The association between the presence of chronic joint pain and global and lobar brain volumes was studied. Subsequently, literature was reviewed and the association of chronic pain and heat pain thresholds with 11 brain regions associated with musculoskeletal pain in previous publications was studied.

RESULTS: Total gray matter volume was smaller in women with chronic pain $(\beta=-0.066, P=.016)$. This effect was primarily driven by lower gray matter volume in the temporal lobe $(\beta=0.086, P=.005)$, the frontal lobe $(\beta=-0.060, P=.039)$, and the hippocampus $(\beta=-0.099, P=.002)$. In addition, we observed that a lower heat pain threshold was associated with smaller volumes of the hippocampus $(\beta=0.017, P=.048)$, the thalamus $(\beta=0.018, P=.009)$, and the anterior cingulate cortex $(\beta=-0.016, P=.037)$. In men, no significant associations were observed.

CONCLUSIONS: The primary identified brain areas, the temporal and frontal lobes and the hippocampus, indicated involvement of emotional processing. The volumetric differences found indicated a sex-specific neuroplasticity in chronic pain. These results emphasized sex-specific and multidisciplinary pain treatment.

C hronic musculoskeletal pain is very common in the general elderly population, with a prevalence up to $50 \%-60 \%$. Experienced chronic joint pain does not always reflect the extent of

Received January 17, 2015; accepted after revision July 11.

From the Departments of Internal Medicine (M.d.K., A.G.U., J.B.J.v.M.), Anaesthesiology (M.d.K., F.J.P.M.H.), Radiology (D.B., W.J.N., M.W.V., M.A.I.), Epidemiology (D.B., H.T., A.H., A.G.U., M.W.V., M.A.I.), Medical Informatics (W.J.N.), and Neurology (M.A.I.), Erasmus MC, University Medical Center, Rotterdam, the Netherlands; and Faculty of Applied Sciences (W.J.N.), Delft University of Technology, Delft, the Netherlands.

This study was funded by the Netherlands Society for Scientific Research VIDI Grant 917103521. The Rotterdam Study is funded by Erasmus Medical Center and Erasmus University (Rotterdam), Netherlands Organization for the Health Research and Development, the Research Institute for Diseases in the Elderly, the Ministry of Education, Culture and Science, the Ministry for Health, Welfare and Sports, the European Commission (DG XII), and the Municipality of Rotterdam.

Please address correspondence to Joyce van Meurs, PhD, Genetic Laboratory Department of Internal Medicine, Room Ee579b, Erasmus MC, MC PO Box 1738, 3000 DR Rotterdam, the Netherlands; e-mail: j.vanmeurs@erasmusmc.nl

- Indicates open access to non-subscribers at www.ajnr.org

三 Indicates article with supplemental on-line table.

http://dx.doi.org/10.3174/ajnr.A4556 objective pathology. ${ }^{1-4}$ Central sensitization plays an important role in the development of chronic joint pain. Chronic pain and central sensitization result in higher vulnerability for developing chronic pain at multiple sites and higher sensitivity for painful stimuli. ${ }^{5}$ Differences in pain processing may be expressed in functional and structural changes in the nervous system. MR imaging allows us to identify brain regions involved in this process of central sensitization, which can provide more insight into chronic pain.

Previous studies that examined structural brain alterations in chronic pain focused on a variety of pain phenotypes, such as migraine, back pain, osteoarthritis, and fibromyalgia. ${ }^{6-15}$ Typically, the study size was small; the largest studies included approximately 100 subjects. The small sample sizes of these studies led to a modest statistical power, thereby influencing the reproducibility of the results. ${ }^{16}$ In addition, all previous reports had a case-control design, which selected individuals who were referred to the clinic as chronic pain cases. As a result, many different areas were shown to associate with a particular pain phenotype but only a few areas of the brain showed consistent associations. For example, 
the thalamus was found to be positively associated with chronic low back pain by Schmidt-Wilcke et al ${ }^{17}$ but negatively associated with chronic low back pain by Apkarian et al. ${ }^{18}$ Regions that are part of the limbic system and signaling pathway were among the identified pain-associated brain areas. Furthermore, each different pain phenotype showed different patterns of structural brain changes, with some overlapping regions, for example, the hippocampus. ${ }^{7}$ Despite the possible identification of structural brain alterations in these selected clinical cases, it remains unclear which brain regions are morphologically altered in chronic pain in the general population. Therefore, in this study, after review of the existing literature, we attempted to replicate previous identified regions to find brain structures robustly associated with musculoskeletal pain.

Individuals with chronic pain are shown to be more sensitive to experimental pain stimuli. Central sensitization can be detected by lower pain thresholds. ${ }^{19-21}$ The stimulus response curve is shifted to the left, which results in lower pain thresholds or higher reported pain intensity scores for a stimulus. The spread of central sensitization, manifested because general hyperalgesia is one of the fundamental processes in the development of chronic pain. ${ }^{22-25}$ Lower pain thresholds, as part of central sensitization, might be associated with structural brain changes. Thus far, the relation between experimental pain and structural brain alterations has only been studied in 1 study of 80 healthy individuals. ${ }^{26}$ In addition, Seminowicz et $\mathrm{al}^{27}$ showed, in a rat model for longterm neuropathic pain, that thermal and mechanical hyperalgesia is associated with structural brain changes.

Given the high prevalence of chronic musculoskeletal pain in the elderly and the burden of chronic musculoskeletal pain on quality of life, more insight into the pathophysiology is necessary to understand chronic pain in the general population and improve treatment options. In this study, we examined, in a large population-based cohort study, the association of chronic musculoskeletal pain and heat pain thresholds with MR imagingbased structural brain changes. We studied changes in global and lobar brain volumes and, in addition, specific brain regions previously reported to be associated with musculoskeletal pain phenotypes.

\section{MATERIALS AND METHODS \\ Study Population: The Rotterdam Study}

The Rotterdam Study is a large prospective population-based cohort study of persons ages 45 years and older. The study design and rationale are described elsewhere in detail. ${ }^{28}$ In summary, the objective of the Rotterdam Study is to investigate the determinants, incidence, and progression of chronic disabling diseases in the elderly. The first cohort, Rotterdam Study I consisted of 7983 persons ages $\geq 55$ years and was initiated in 1989 . This study population was extended in 2000, which added 3011 participants in Rotterdam Study II and, in 2005, added another 3932 subjects ages $\geq 45$ years in Rotterdam Study III. All the participants were examined in detail at baseline. In summary, a home interview was conducted, and the subjects had an extensive set of examinations at the research center.

The participants in the study as presented here were derived from the Rotterdam Scan Study, ${ }^{29}$ an ongoing population- based cohort study that investigated brain changes on MR imaging, which is embedded in the Rotterdam Study. The Rotterdam Study has been approved by the medical ethics committee according to the Population Study Act Rotterdam Study executed by the Ministry of Health, Welfare and Sports of the Netherlands. Written informed consent was obtained from all the participants.

\section{MR Imaging Acquisition and Processing}

MR imaging scanning was performed on a $1.5 \mathrm{~T}$-scanner with an 8-channel head coil (GE Healthcare, Milwaukee, Wisconsin). An extensive description of the scan protocol is provided elsewhere. ${ }^{29}$ In short, the protocol included a T1-weighted sequence, a protonattenuation weighted sequence, and a fluid-attenuated inversion recovery sequence. ${ }^{29}$

Automated brain tissue classification based on a k-nearestneighbor-classifier algorithm extended with white matter lesion segmentation $^{30,31}$ was used to quantify global and lobar brain volume, gray matter volume, white matter volume, and intracranial volume (in $\mathrm{mL}^{3}$ ). This method has been optimized and validated for the Rotterdam Scan Study and includes a standardized and validated image analysis workflow to enable objective, accurate, and reproducible extraction of brain volumes. ${ }^{29}$ Segmentation and labeling of smaller specific brain regions was performed by FreeSurfer version 4.5 (http://surfer.nmr.mgh.harvard.edu/). ${ }^{26}$ This procedure automatically assigns a neuroanatomic label to each voxel in an MR imaging volume based on probabilistic information obtained from a manually labeled training set. FreeSurfer was used with the default parameters, including skull-stripping and using the automatically generated brain mask.

\section{Review of the Literature and Selection of Candidate Replication Regions}

We systematically searched the literature by using the PubMed data base on July 7, 2014, with search terms "structural and brain and MR imaging and chronic and pain." In addition, we screened the references of included articles to extend the search. The review of literature identified 83 articles, of which 68 articles were excluded based on the following selection criteria: 1) the article represents original data, and 2) the trait of interest is musculoskeletal pain. Finally, 15 studies were included in the total review.

\section{Assessment of Chronic Joint Pain}

All the participants completed a pain homunculus to report chronic painful sites in the body. The pain homunculus showed a picture of the front and the back of the human body. The participants were asked the following question, "Did you have pain anywhere in your body, for at least half of the days, during the last six weeks?" Circles were drawn by the participant around the painful areas. The homunculi were scored by using a template that assigned 14 different joint pain regions (eg, neck, shoulders, elbows, hands, low back, hips, knees, feet). Chronic joint pain was defined as subjects having one or more painful sites. Furthermore, participants should have visited a medical physician at least once for this chronic joint 
Table 1: Selected brain regions for analysis

\begin{tabular}{|c|c|c|c|c|}
\hline Brain Region & Reference & $+/-$ & $N$ & Chronic Pain Disorder \\
\hline \multirow[t]{4}{*}{ Thalamus } & Apkarian et al, $2004^{18}$ & - & 52 & CLBP \\
\hline & Schmidt-Wilcke et al, $2006^{17}$ & + & 36 & CLBP \\
\hline & Schmidt-Wilcke et al, $2007^{40}$ & - & 42 & Fibromyalgia \\
\hline & Ivo et al, $2013^{9}$ & - & 28 & CLBP \\
\hline \multirow[t]{3}{*}{ S1 } & Rodriguez-Raecke et al, $2009^{39}$ & - & 32 & Hip OA \\
\hline & Seminowicz et al, $2011^{41}$ & - & 34 & CLBP \\
\hline & Kong et al, $2013^{36}$ & + & 36 & CLBP \\
\hline \multirow[t]{5}{*}{ Insular cortex } & Kuchinad et al, $2007^{37}$ & - & 20 & Fibromyalgia \\
\hline & Rodriguez-Raecke et al, $2009^{39}$ & - & 32 & Hip OA \\
\hline & Valet et al, $2009^{42}$ & - & 39 & Pain syndrome (DSM IV) \\
\hline & Robinson et al, $2011^{11}$ & - & 25 & Fibromyalgia \\
\hline & Seminowicz et al, $2011^{41}$ & - & 34 & CLBP \\
\hline \multirow{5}{*}{$\begin{array}{l}\text { Anterior cingulate } \\
\text { cortex }\end{array}$} & Burgmer et al, $2009^{34}$ & - & 28 & Fibromyalgia \\
\hline & Valet et al, $2009^{42}$ & - & 39 & Pain syndrome (DSM IV) \\
\hline & Rodriguez-Raecke et al, $2009^{39}$ & - & 32 & Hip OA \\
\hline & Seminowicz et al, $2011^{41}$ & - & 34 & CLBP \\
\hline & Jensen et al, $2013^{35}$ & - & 39 & Fibromyalgia \\
\hline \multirow[t]{5}{*}{ Midcingulate cortex } & Kuchinad et al, $2007^{37}$ & - & 20 & Fibromyalgia \\
\hline & Buckalew et al, $2008^{33}$ & - & 16 & CLBP \\
\hline & Wood et al, $2009^{43}$ & - & 14 & Fibromyalgia \\
\hline & Robinson et al, $2011^{11}$ & - & 25 & Fibromyalgia \\
\hline & Ivo et al, $2013^{9}$ & - & 28 & CLBP \\
\hline \multirow{3}{*}{$\begin{array}{l}\text { Prefrontal cortex } \\
\text { dorsolateral }\end{array}$} & Apkarian et al, $2004^{18}$ & - & 52 & CLBP \\
\hline & Seminowicz et al, $2011^{41}$ & - & 34 & CLBP \\
\hline & Ivo et al, $2013^{9}$ & - & 28 & CLBP \\
\hline \multirow{3}{*}{$\begin{array}{l}\text { Prefrontal cortex } \\
\text { ventrolateral }\end{array}$} & Rodriguez-Raecke et al, $2009^{39}$ & - & 32 & Hip OA \\
\hline & Burgmer et al, $2009^{34}$ & - & 28 & Fibromyalgia \\
\hline & Seminowicz et al, $2011^{41}$ & - & 34 & CLBP \\
\hline \multirow{4}{*}{$\begin{array}{l}\text { Posterior cingulate } \\
\text { cortex }\end{array}$} & Kuchinad et al, $2007^{37}$ & - & 20 & Fibromyalgia \\
\hline & Valet et al, $2009^{42}$ & - & 39 & Pain syndrome (DSM IV) \\
\hline & Wood et al, $2009^{43}$ & - & 14 & Fibromyalgia \\
\hline & Robinson et al, $2011^{11}$ & - & 25 & Fibromyalgia \\
\hline \multirow[t]{4}{*}{ Orbitofrontal cortex } & Schmidt-Wilcke et al, $2007^{40}$ & + & 42 & Fibromyalgia \\
\hline & Valet et al, $2009^{42}$ & - & 39 & Pain syndrome (DSM IV) \\
\hline & Rodriguez-Raecke et al, $2009^{39}$ & - & 32 & Hip OA \\
\hline & Seminowicz et al, $2011^{41}$ & - & 34 & CLBP \\
\hline \multirow[t]{2}{*}{ Hippocampus } & Lutz et al, $2008^{38}$ & - & 60 & Fibromyalgia \\
\hline & Zimmerman et al, $2009^{14}$ & - & 20 & Chronic pain \\
\hline \multirow[t]{2}{*}{ Amygdala } & Burgmer et al, $2009^{34}$ & - & 28 & Fibromyalgia \\
\hline & Rodriguez-Raecke et al, $2009^{39}$ & - & 32 & Hip OA \\
\hline
\end{tabular}

Note:-_+ indicates larger volume in chronic pain; -, smaller volume in chronic pain; CLBP, chronic low back pain; OA, osteoarthritis; DSMIV, Diagnostic and Statistical Manual of Mental Disorders, 4th Edition.

Table 2: Baseline characteristics of the study population

\begin{tabular}{lccc}
\hline & Total $(\boldsymbol{n}=3376)$ & Men $(\boldsymbol{n}=1525)$ & Women $(\boldsymbol{n}=1851)$ \\
\hline Mean age, $y$ & $60.3 \pm 8.7$ & $60.4 \pm 8.7$ & $60.1 \pm 8.7$ \\
Chronic pain, no. (\%) & $1191(35.3)$ & $414(27.1)$ & $777(42.0)$ \\
Mean intracranial volume, $\mathrm{mL}$ & $1126 \pm 119$ & $1203 \pm 102$ & $1062 \pm 91$ \\
Positive CESD, no. $(\%)$ & $328(8.5)$ & $81(4.6)$ & $247(11.7)$ \\
Mean heat pain threshold, ${ }^{\circ} \mathrm{C}$ & $47.2 \pm 3.2$ & $48.0 \pm 2.7$ & $46.6 \pm 3.4$ \\
$(n=1538)$ & & & \\
\hline
\end{tabular}

Note:-CESD indicates Center for Epidemiologic Studies Depression scale.

pain. This information was derived from the questionnaire during the home interview.

In addition, because we used a more heterogenic pain phenotype compared with previous studies, we defined 3 chronic pain phenotypes to be able to compare our results better with previous literature. The phenotypes examined in the studies, also selected for the review, were fibromyalgia, chronic low back pain, and hip osteoarthritis pain. Because we did not have data on fibromyalgia, we used chronic widespread pain as a proxy. Chronic widespread pain was defined as subjects having pain in the left side of the body, in the right side of the body, above the waist, below the waist, and in the axial skeleton (by following the Fibromyalgia Criteria of the American College of Rheumatology). ${ }^{32}$ Hip osteoarthritis pain was defined as a Kellgren-Lawrence score of $\geq 2$ and chronic pain in the same hip. Controls in these analyses were individuals without chronic pain.

\section{Heat Pain Threshold Measurement}

For the measurement of heat pain threshold, we used a commercially available thermosensory analyzer, the TSA II (Medoc Advanced Medical Systems, Durham, North Carolina). The probe, with a surface of $2 \mathrm{~cm}$ by $2 \mathrm{~cm}$ was placed on the ventral site of the nondominant forearm. The start temperature of the probe was $32^{\circ} \mathrm{C}$. The temperature increased by $2^{\circ} \mathrm{C}$ per second, and the participant was asked to push a large quiz button when the temperature became painful. This measurement was repeated 5 times; the mean of the last 3 measurements was used. Because this was measured approximately 5 years after the brain MR imaging was acquired, we included only those individuals with a stable pain state. Individuals with chronic pain at both the time of brain MR imaging and chronic pain at the time of the heat pain threshold measurement were considered as cases, individuals without chronic pain at both time points were considered as controls.

\section{Population for Analysis}

A total of 4898 participants who were part of Rotterdam Study I, Rotterdam Study II, or Rotterdam Study III were invited to undergo an MR imaging. We excluded individuals who had dementia ( $n=30)$ or had MR imaging contraindications $(n=389)$. Of 4479 eligible persons, 4082 (91\%) participated. Due to physical inability, imaging could not be performed in 44 individuals. Of 4038 persons with complete MR imaging examinations, 59 had to be excluded because of motion artifacts or susceptibility artifacts on their scans, which left 3979 persons with complete brain MR imaging. Pain data were not available for 87 of these persons, whereas data on the need for medical treatment for the pain medication was not available for 516 individuals, which left 3376 persons for the analyses. For the association analysis with the heat 
pain threshold measurements, a subset of 839 individuals with a stable pain state as described above was used.

\section{Statistical Analysis}

Linear regression models were used to test the association between chronic musculoskeletal pain, heat pain thresholds, and brain volumes. We calculated $z$ scores $(\mathrm{X}-$ mean/SD) of the brain volumes to allow direct comparability between the various effect estimates for the analyses between pain and the different brain structures. $Z$ score standardization is done in the common way by (brain volume - mean brain volume)/SD.

Because previous studies found differences on pain-associated regions between the sexes, we stratified for sex and adjusted for age, intracranial volume, and the presence of depression according to the self-reporting Center for Epidemiologic Studies Depression scale, defined by a score of $>16$. SPSS version 21.0 (SPSS Statistics for Windows; IBM, Armonk, New York) was used for the association analysis. The null hypothesis tested was that there is no difference in brain volumes in the studied structures between individuals without chronic musculoskeletal and those with chronic musculoskeletal pain. The second hypothesis tested was that brain volumes of the studied structures are not associated with heat pain thresholds. A $P$ value of $<.05$ was considered statistically significant.

\section{Association Analysis with Chronic Musculoskeletal Pain and Heat Pain Threshold}

First, we performed an association analysis without hypothesizing where to expect structural alterations in the brain in chronic joint pain. Therefore, we investigated the association of global volumes of gray and white matter with chronic joint pain. Next, we segmented the brain into the 4 main lobes (frontal, temporal, parietal, and occipital). Gray and white matter volumes in the different lobes were then studied for the association with chronic joint pain. Subsequently, we investigated the association of chronic joint pain with the volumes of the selected regions reported in the literature (Table 1).

In the effort to replicate previous findings, we examined the association of chronic widespread pain as a proxy for fibromyalgia, chronic low back pain, and hip osteoarthritis pain with brain region volumes in our sample. In addition, we investigated the association of the brain region volumes with heat pain thresholds.

\section{RESULTS}

Population characteristics for the 3892 persons with brain MR imaging and chronic pain information are shown in Table 2. The prevalence of chronic pain and depression was higher in women compared with men, and the total intracranial volume was smaller in women. Heat pain thresholds were higher in men compared with women $\left(48.0^{\circ} \mathrm{C}\right.$ vs $\left.46.6^{\circ} \mathrm{C}\right)$.

\section{Chronic Joint Pain and Global and Lobar Brain Volumes}

The associations between chronic musculoskeletal pain and global and lobar brain volumes are shown in Fig 1. No significant association between chronic musculoskeletal pain and total brain volume was observed in the overall population.
When we stratified according to sex, we observed a significant association with total gray matter in the women. Total gray matter was smaller in women with chronic pain (difference in $Z$ score, $\beta=-0.066 ; P=.016$ ). When we divided the brain into the 4 main lobes, this lower gray matter volume was found to be primarily located in the temporal lobe $(\beta=-0.086, P=.005)$ and the frontal lobe $(\beta=-0.060, P=.039)$. In the men, we did not find differences in global brain volumes between participants with and those without chronic pain. Excluding participants with depression defined by a Center for Epidemiologic Studies Depression scale score of $>16$ ( 81 men, 247 women) in the sensitivity analysis did not alter these effects.

\section{Chronic Joint Pain and Predefined Brain Regions}

Next, we focused our analysis on volumes of specific brain regions that were previously reported in the literature as being associated with musculoskeletal pain phenotypes (Table 1). These regions were selected on the basis of a systematic review. In total, 15 studies that assessed the relationship between brain structures and chronic pain were included in this review. ${ }^{9,11,14,17,33-43}$ All brain regions previously reported to be significantly associated with chronic pain are shown in the On-line Table, together with the direction of the effect. We decided to include the brain regions that were reported to be associated with musculoskeletal pain at least twice. The 11 selected regions are shown in Table 1, together with the sample size of each study, which were all fewer than 100 individuals. Segmentation of the 11 brain regions was done in 4898 individuals with the use of FreeSurfer software. We observed a significantly smaller hippocampal volume in women with chronic musculoskeletal pain $(\beta=-0.099, P=.002)$, whereas men showed a similar trend, though this did not reach significance (Fig 2). When data for men and women were analyzed together, a highly significant association was seen $(\beta=$ $\left.-0.092, P=4.69 \times 10^{-4}\right)$.

We next studied specific pain subtypes to mimic earlier reports. We studied chronic widespread pain, chronic low back pain, and hip osteoarthritis pain separately as determinants for brain region volumes. For the analyses of chronic widespread pain and hip osteoarthritis pain, we observed similar effect directions for hippocampal volume but only for chronic low back pain was statistical significance reached $(\beta=-0.115, P=.033)$.

Among the subset with heat pain threshold measurements, we observed only in the women, a positive association between heat pain thresholds and hippocampal volume, thalamic volume, and the volume of the anterior cingulate cortex (Fig 3), which indicated that lower pain sensitivity thresholds, which represent central sensitization, were indeed coinciding with smaller hippocampal, thalamic, and anterior cingulate cortex volumes.

\section{DISCUSSION}

In this large population-based cohort of individuals with ages $\geq 45$ years, we observed that chronic musculoskeletal pain was associated with a smaller global gray matter volume in the women. This smaller volume was primarily found in the temporal lobe, more specifically, in the hippocampus, part of the limbic system. In addition, again in the women, a lower heat 

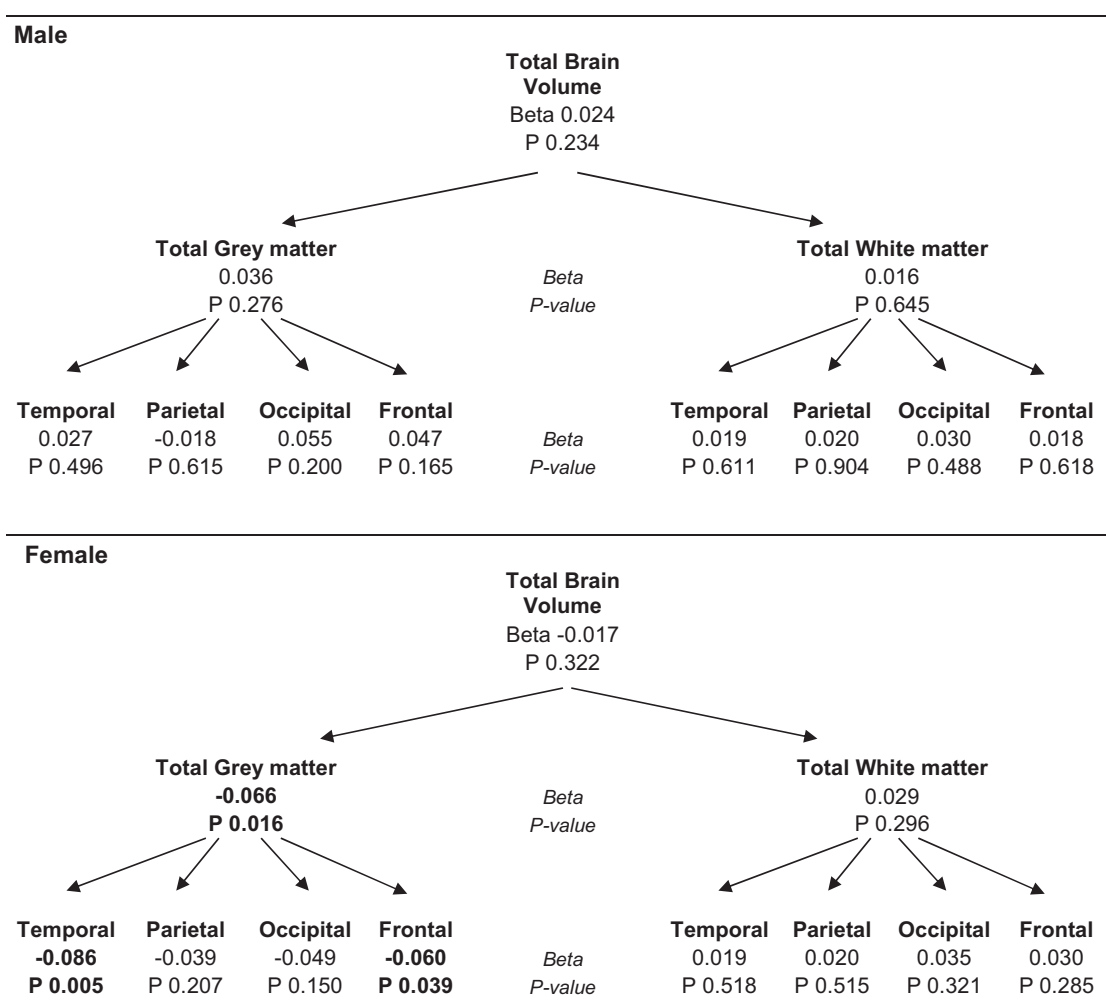

FIG 1. Chronic musculoskeletal pain and global brain volumes. Analyses adjusted for age, intracranial volume and depression. $\beta$ is the difference in standardized brain volume for individuals with chronic joint pain compared with those without chronic joint pain.

pain threshold, which indicates higher (central) pain sensitivity, was associated with smaller volumes of the hippocampus, thalamus, and anterior cingulate cortex, regions that are involved in the limbic system and descending pain processing pathways. In the men, no significant associations between chronic joint pain or heat pain thresholds and brain volumes were observed.

To our knowledge, this is the first study that examined the association between chronic joint pain and structural brain changes in a population-based study. The number of studied patients was approximately 30 times larger than any previous study that examined the relationship between chronic pain and structural brain changes. Previous studies that examined structural brain alterations in pain consisted mostly of small and very specific clinical patient populations. ${ }^{6-13,15}$ We used a hierarchical approach in studying brain structural differences. We first examined global brain tissue volumes and lobar volumes. Subsequently, we investigated those brain regions that were reported at least twice in the previous literature to be associated with chronic musculoskeletal pain. This strategy was chosen because previous studies showed inconsistent findings, which might be due to the different clinical pain phenotypes and low power that led to conflicting results, as highlighted previously. ${ }^{16}$ Indeed, we were unable to replicate most of the previously implicated brain regions, which indicated that these brain regions are not consistently associated with chronic musculoskeletal pain.

The development of the brain is sex specific and influenced by sex hormones. It is shown that sex differences are also present with respect to pain processing. ${ }^{44-48}$ Therefore, we stratified our analyses according to sex. In women, gray matter in the temporal lobe and, especially, in the hippocampus was smaller in those with chronic pain. The hippocampus has previously been suggested as one of the altered structures in the brain in several pain states. ${ }^{6,7}$ In women, this involvement of the limbic system, therefore, could indicate a more emotional coping of pain.

Smaller volumes of the hippocampus, thalamus, and anterior cingulate cortex were also associated with lower heat pain thresholds in women in our study. The thalamus is important in the descending inhibitory signaling, which is known to be compromised in central sensitization in chronic pain, ${ }^{5,7}$ which makes our findings more plausible. To our knowledge, this is the first study that examined the association between heat pain thresholds and brain structure volumes. A limitation of the analysis of heat pain threshold and brain volumes was that the 2 measurements were done during 2 different visits, with several years in between. To minimize this time bias, we examined only those participants who had chronic pain at both visits versus those who had no chronic pain at both visits.

In this study, we examined both the presence of chronic musculoskeletal pain and also heat pain sensitivity thresholds and their relationship to structural brain alterations. The presence of chronic musculoskeletal pain is a very subjective phenotype because it is determined by using questionnaires, and there is no test to measure pain. Heat pain thresholds are closely related to the sensitivity for developing chronic pain and for having chronic pain, which, therefore, makes it a more objective measure for chronic pain. The combined use of questionnaire data and heat pain thresholds to find associations with structural brain alterations, therefore, strengthens the results.

A possible disadvantage of population-based studies is the more heterogeneous pain phenotype compared with the selected clinical populations. However, this reflects the situation in the general population and shows that central sensitization occurs not only in a selected patient population. In addition, chronic pain in community-dwelling subjects represents a huge problem, which affected $35.3 \%$ of our study population. However, its nature and cause is poorly understood, and often no apparent reason can be assigned to the chronic pain state. Studying pain in an unselected population without the selection bias of clinical reference could provide new insight in possible pathways involved in any chronic pain state. 


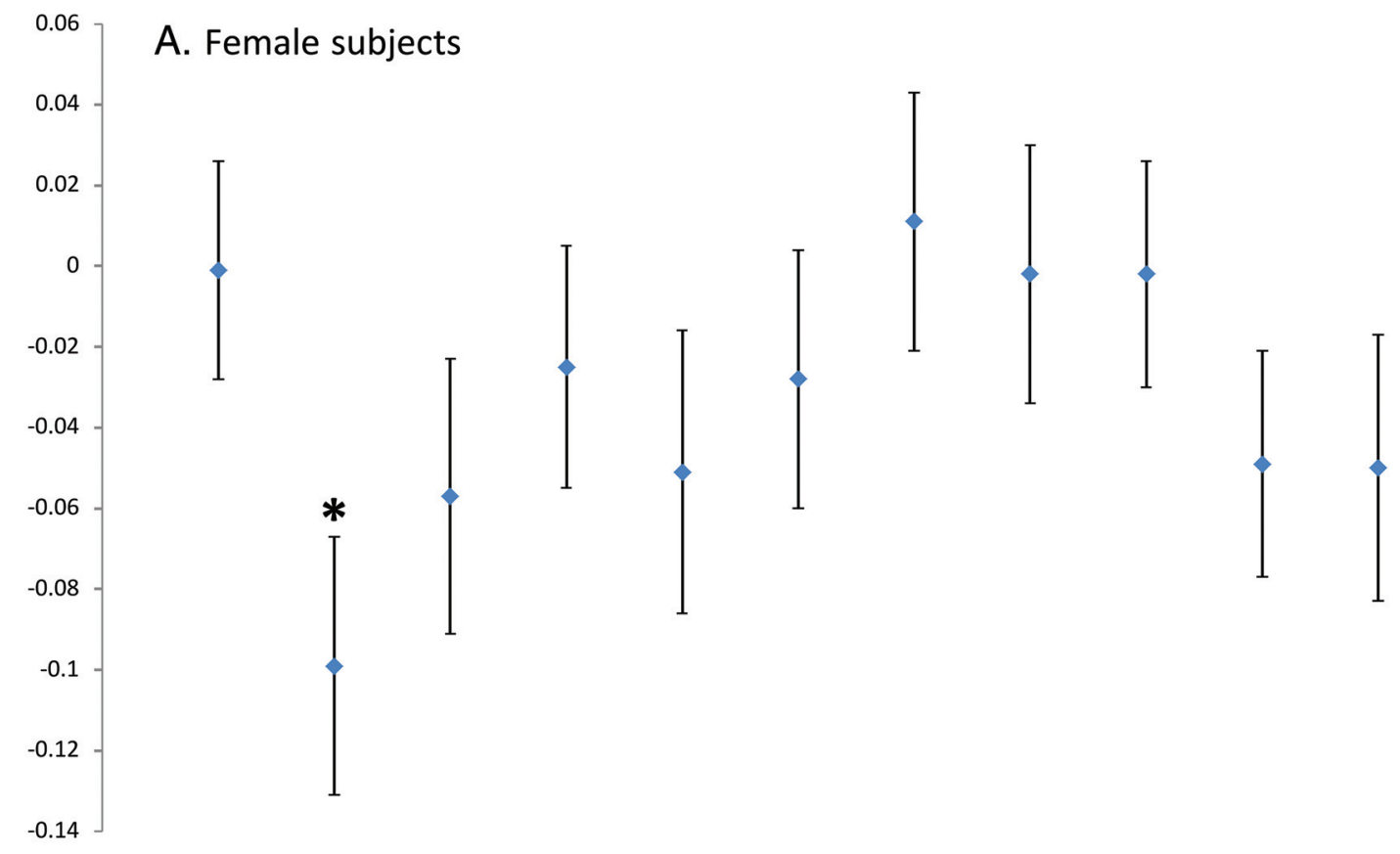

\begin{tabular}{|c|c|c|c|c|c|c|c|c|c|c|c|}
\cline { 2 - 10 } \multicolumn{1}{c|}{} & Thal & Hippo & Amyg & OFC & VIPFC & dlPFC & PCC & MCC & ACC & Insula & S1 \\
\hline Beta & -0.001 & -0.099 & -0.057 & -0.025 & -0.051 & -0.028 & 0.011 & -0.002 & -0.002 & -0.049 & -0.05 \\
\hline
\end{tabular}

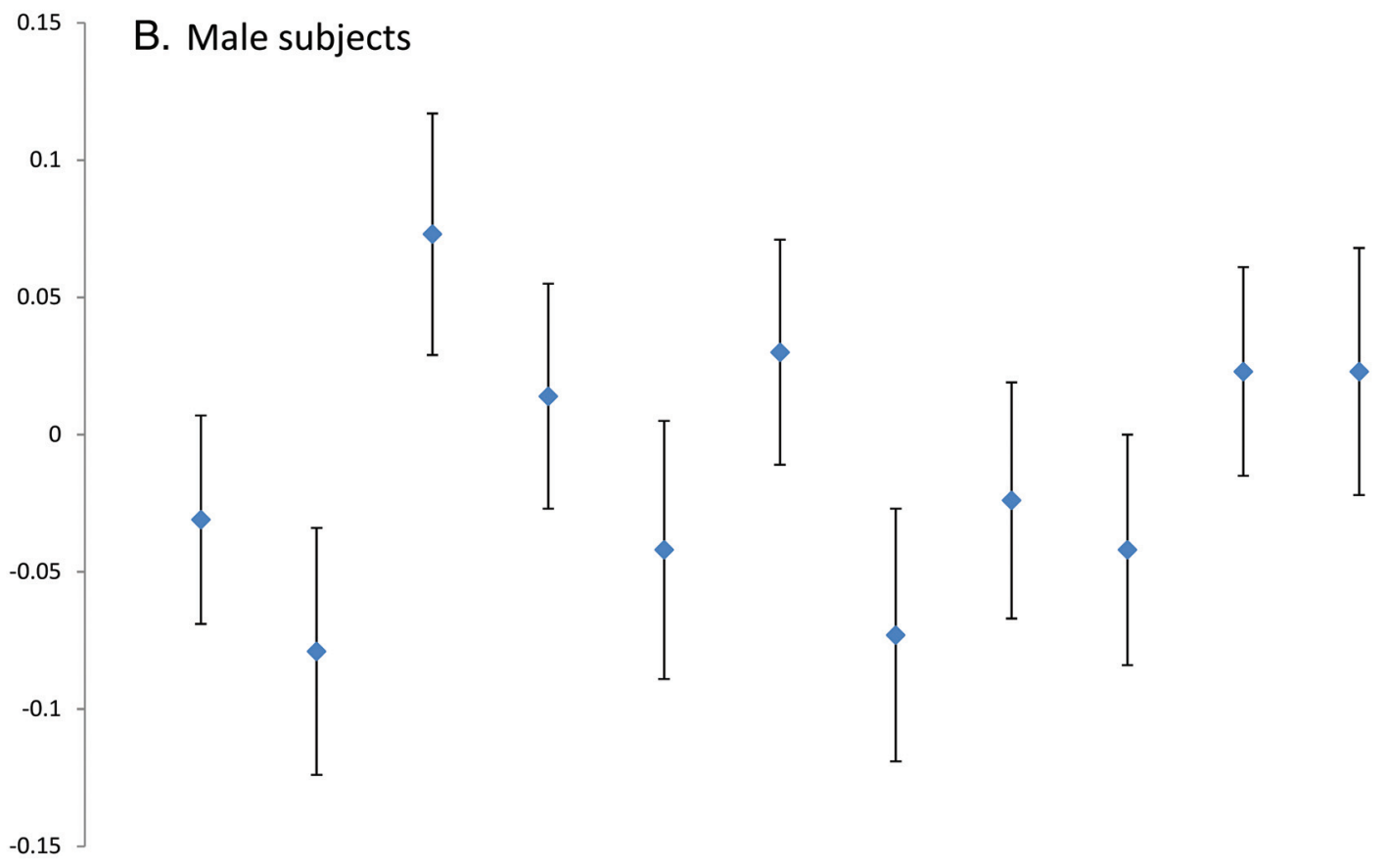

\begin{tabular}{|c|c|c|c|c|c|c|c|c|c|c|c|}
\cline { 2 - 11 } \multicolumn{1}{c|}{} & Thal & Hippo & Amyg & OFC & vIPFC & dIPFC & PCC & MCC & ACC & Insula & S1 \\
\hline Beta & -0.031 & -0.079 & 0.073 & 0.014 & -0.042 & 0.03 & -0.073 & -0.024 & -0.042 & 0.023 & 0.023 \\
\hline
\end{tabular}

FIG 2. Brain volumes in regions of the limbic system and signal processing in relation to chronic musculoskeletal pain in $(A)$ female and $(B)$ male subjects. Plots represent $\beta$ and standard error. $\beta$ is the difference in standardized brain volume for individuals with chronic joint pain compared with those without chronic joint pain. Analyses were adjusted for age, intracranial volume, and depression. ${ }^{*} P=.002$. Thal indicates thalamus; Hippo, hippocampus; Amyg, amygdala; OFC, orbitofrontal cortex; vlPFC, ventrolateral prefrontal cortex; dlPFC, dorsolateral prefrontal cortex; PCC, posterior cingulate cortex; MCC, midcingulate cortex; ACC, anterior cingulate cortex; Insula, insular cortex; S1, primary somatosensory cortex.

The cross-sectional aspect of this study made us unable to speculate on the brain volume changes being a cause or an effect in the pathology of chronic pain. A previous study on structural brain changes in pain related to severe hip osteoarthritis showed normalization of these differences after hip replacement surgery, which indicates that the pain is causing structural brain changes, ${ }^{39}$ 


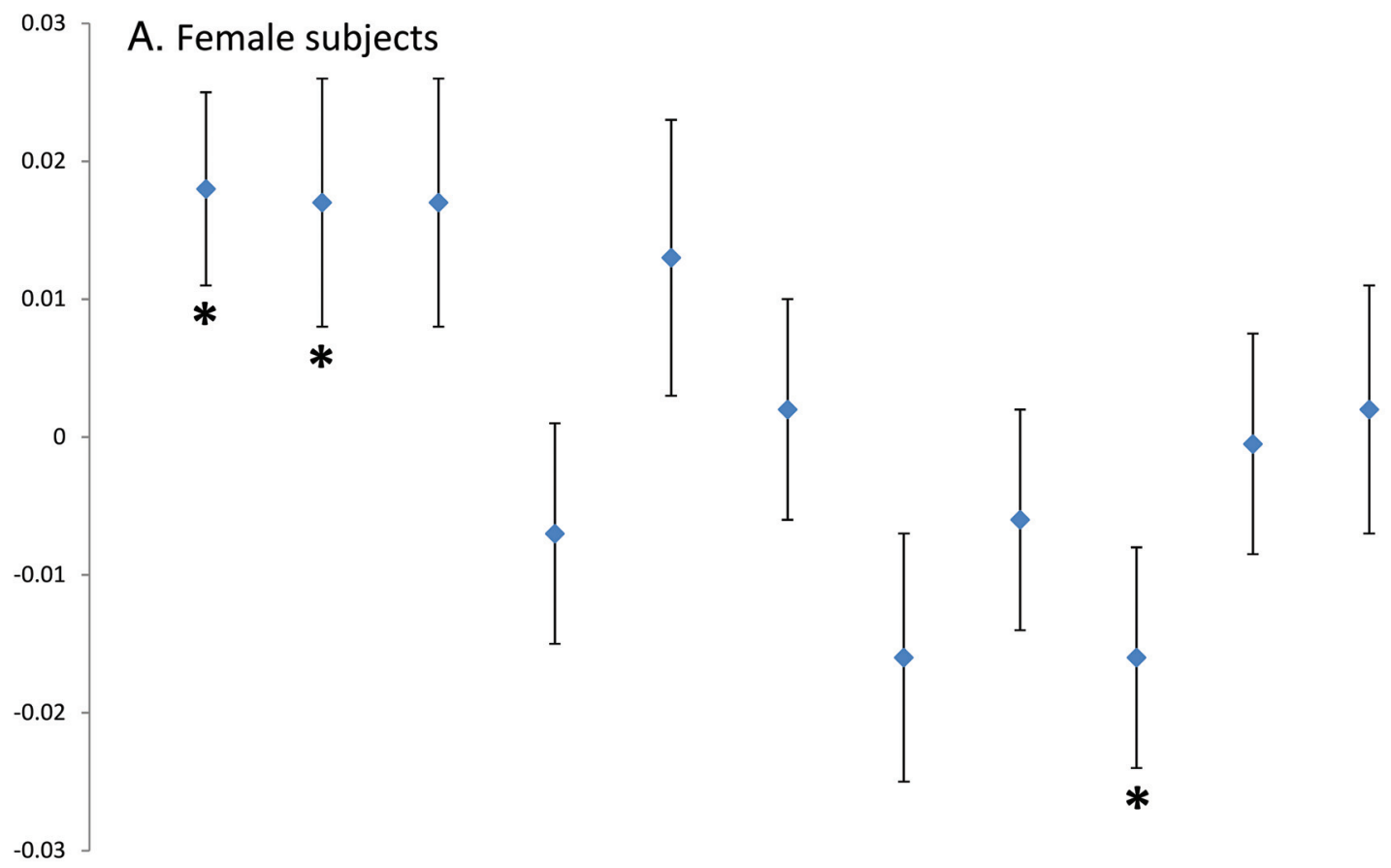

\begin{tabular}{|c|c|c|c|c|c|c|c|c|c|c|c|}
\cline { 2 - 11 } \multicolumn{1}{c|}{} & Thal & Hippo & Amyg & OFC & vIPFC & dIPFC & PCC & MCC & ACC & Insula & S1 \\
\hline Beta & 0.018 & 0.017 & 0.017 & -0.007 & 0.013 & 0.002 & -0.016 & -0.006 & -0.016 & -0.0005 & 0.002 \\
\hline
\end{tabular}

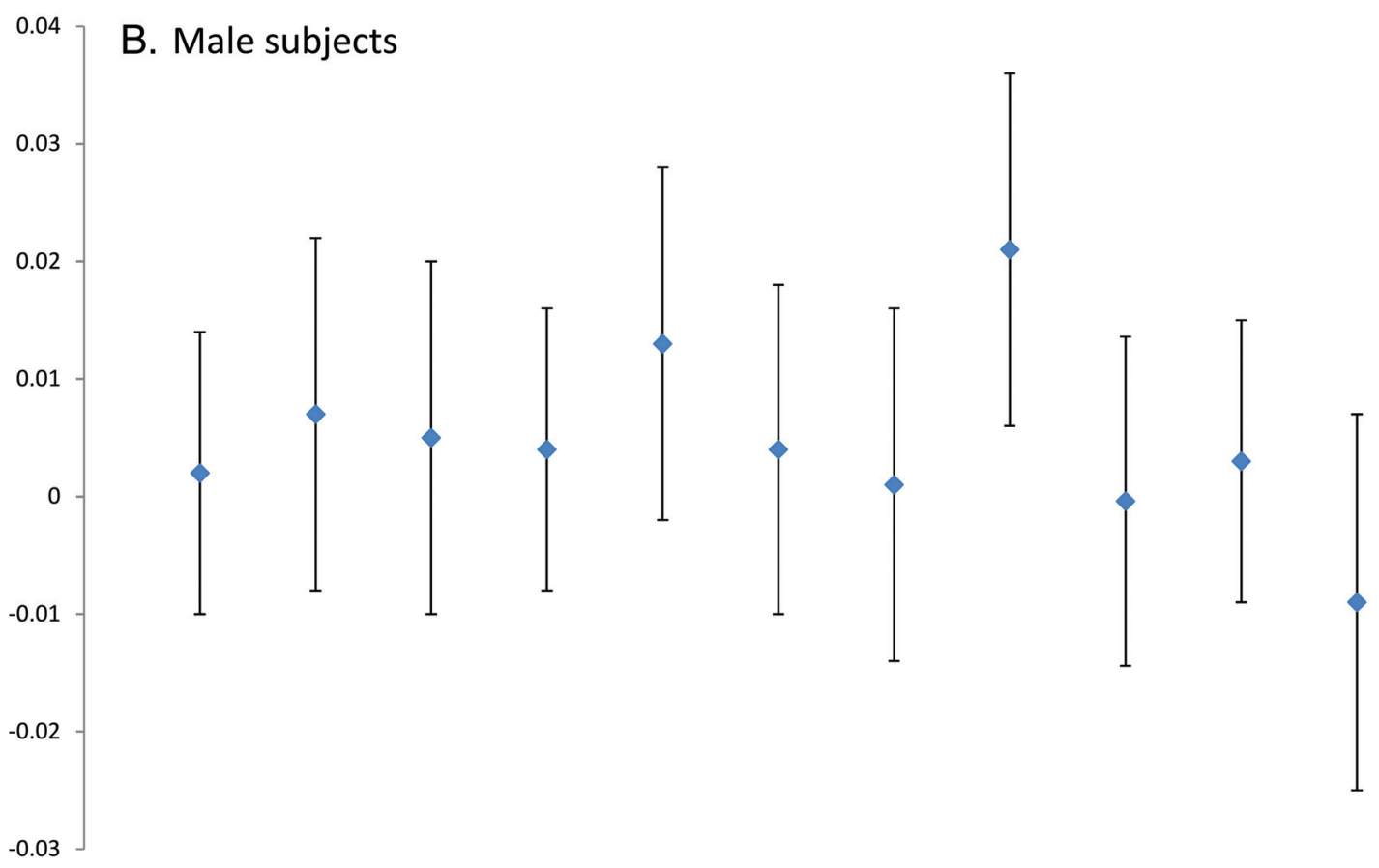

\begin{tabular}{|c|c|c|c|c|c|c|c|c|c|c|c|}
\cline { 2 - 11 } \multicolumn{1}{c|}{} & Thal & Hippo & Amyg & OFC & vIPFC & dIPFC & PCC & MCC & ACC & Insula & S1 \\
\hline Beta & 0.002 & 0.007 & 0.005 & 0.004 & 0.013 & 0.004 & 0.001 & 0.021 & -0.0004 & 0.003 & -0.009 \\
\hline
\end{tabular}

FIG 3. Quantitative sensory testing (heat pain threshold) and structural brain alterations in ( $A$ ) female and (B) male subjects. Plots represent $\beta$ and standard error. $\beta$ is the difference in standardized brain volume per degree of temperature (Celsius); analyses were adjusted for age, intracranial volume, and depression. ${ }^{*} P<.05$. Thal indicates thalamus; Hippo, hippocampus; Amyg, amygdala; OFC, orbitofrontal cortex; vlPFC, ventrolateral prefrontal cortex; dIPFC, dorsolateral prefrontal cortex; PCC, posterior cingulate cortex; MCC, midcingulate cortex; ACC, anterior cingulate cortex; Insula, insular cortex; Sl, primary somatosensory cortex.

but larger longitudinal studies are necessary for confirmation because sample size was small in this study $(n=10)$.

Depression coincides with chronic musculoskeletal pain, and, because both might affect the limbic system, ${ }^{11}$ we adjusted the analysis for the presence of depression. In addition, excluding persons with depression from the model did not change the re- 
sults, which indicated that our findings were not influenced by the presence of depression.

Because we started our study hypothesis-free and continued examining smaller regions, we performed a considerable amount of tests, which might have led to spurious findings. If we would have used a Bonferroni correction for the statistically significant $P$ value for the brain structures, then this would result in a $P$ value of $.05 / 11=.004$; this is when assuming independency of the tests. Many results would still be considered statistically significant. However, not all of the tests were independent because the smaller regions were included in the larger lobes. Therefore, deciding which exact $P$ value to use would have been challenging. In addition, the performed analyses were not hypothesis-free because we tried to replicate previous published results. Moreover, especially in the women, we showed very consistent and robust findings, with increasing effect sizes when we narrowed the examined regions.

\section{CONCLUSIONS}

In this large population-based study, we found that chronic musculoskeletal pain was associated with structural changes in parts of the limbic system in the brain. The hippocampus, especially, showed a very consistent and strong relationship with chronic joint pain and heat pain thresholds in women, which indicated a key role in the development of central sensitization and chronic pain. Structural alterations in the brain in individuals with chronic pain support the presence of central sensitization. This process of central sensitization increases the risk for a longer period of chronic pain and increases the risk for developing chronic pain at other sites. ${ }^{5}$ These results stress the importance of a multidisciplinary and sex-specific therapeutic approach to improve successful treatment.

Disclosures: Wiro Niessen—RELATED: Grant: Dutch Science Foundation, ${ }^{\star}$ EU, ${ }^{\star}$ Comments: We have grants from the Netherlands Science Foundation and EU (7th framework programme) supporting our work in neuroimage analysis; UNRELATED: Consultancy: Quantib BV, * Comments: I am cofounder, and scientific director of Quantib $\mathrm{BV}$, an Erasmus MC spin-off. I am detached as consulted to this company for $0.2 \mathrm{fte}$; Stock/Stock Options: I am cofounder and stock-holder of Quantib BV. Henning Tiemeier—RELATED: Grant: Dutch Medical Research Council,* ZonMw VIDI, ${ }^{*}$ Comments: Governmental research funding agency; UNRELATED: Grants/Grants Pending: Grants unrelated to work, all from nonprivate agencies such as EU,* Dutch Medical Research agency* or Sophia Foundation for Scientific Research,* a local nonprofit body. *Money paid to the institution.

\section{REFERENCES}

1. Bedson J, Croft PR. The discordance between clinical and radiographic knee osteoarthritis: a systematic search and summary of the literature. BMC Musculoskelet Disord 2008;9:116 CrossRef Medline

2. Dieppe PA, Lohmander LS. Pathogenesis and management of pain in osteoarthritis. Lancet 2005;365:965-73 CrossRef Medline

3. Hunter DJ, McDougall JJ, Keefe FJ. The symptoms of osteoarthritis and the genesis of pain. Rheum Dis Clin North Am 2008;34:623-43 CrossRef Medline

4. Lawrence JS, Bremner JM, Bier F. Osteo-arthrosis. Prevalence in the population and relationship between symptoms and $x$-ray changes. Ann Rheum Dis 1966;25:1-24 Medline

5. Woolf CJ. Central sensitization: implications for the diagnosis and treatment of pain. Pain 2011;152(3 suppl):S2-15 CrossRef Medline

6. Baliki MN, Schnitzer TJ, Bauer WR, et al. Brain morphological signatures for chronic pain. PLoS One 2011;6:e26010 CrossRef Medline

7. Davis KD, Moayedi M. Central mechanisms of pain revealed through functional and structural MRI. J Neuroimmune Pharmacol 2013;8:518-34 CrossRef Medline

8. Harvey AK, Taylor AM, Wise RG. Imaging pain in arthritis: advances in structural and functional neuroimaging. Curr Pain Headache Rep 2012;16:492-501 CrossRef Medline

9. Ivo R, Nicklas A, Dargel J, et al. Brain structural and psychometric alterations in chronic low back pain. Eur Spine J 2013;22:1958-64 CrossRef Medline

10. May, A. Chronic pain may change the structure of the brain. Pain 2008;137:7-15 CrossRef Medline

11. Robinson ME, Craggs JG, Price DD, et al. Gray matter volumes of pain-related brain areas are decreased in fibromyalgia syndrome. J Pain 2011;12:436-43 CrossRef Medline

12. Smallwood RF, Laird AR, Ramage AE, et al. Structural brain anomalies and chronic pain: a quantitative meta-analysis of gray matter volume. J Pain 2013;14:663-75 CrossRef Medline

13. Tracey I, Bushnell MC. How neuroimaging studies have challenged us to rethink: is chronic pain a disease? J Pain 2009;10:1113-20 CrossRef Medline

14. Zimmerman ME, Pan JW, Hetherington HP, et al. Hippocampal correlates of pain in healthy elderly adults: a pilot study. Neurology 2009;73:1567-70 CrossRef Medline

15. Henry DE, Chiodo AE, Yang W. Central nervous system reorganization in a variety of chronic pain states: a review. $P M R$ 2011;3: 1116-25 CrossRef Medline

16. Button KS, Ioannidis JP, Mokrysz C, et al. Power failure: why small sample size undermines the reliability of neuroscience. Nat Rev Neurosci 2013;14:365-76 CrossRef Medline

17. Schmidt-Wilcke T, Leinisch E, Gänssbauer S, et al. Affective components and intensity of pain correlate with structural differences in gray matter in chronic back pain patients. Pain 2006;125:89-97 CrossRef Medline

18. Apkarian AV, Sosa Y, Sonty S, et al. Chronic back pain is associated with decreased prefrontal and thalamic gray matter density. $J \mathrm{Neu}$ rosci 2004;24:10410-105 CrossRef Medline

19. Puta C, Schulz B, Schoeler S, et al. Enhanced sensitivity to punctate painful stimuli in female patients with chronic low back pain. $B M C$ Neurol 2012;12:98 CrossRef Medline

20. Staud R, Weyl EE, Price DD, et al. Mechanical and heat hyperalgesia highly predict clinical pain intensity in patients with chronic musculoskeletal pain syndromes. J Pain 2012;13:725-35 CrossRef Medline

21. Suokas AK, Walsh DA, McWilliams DF, et al. Quantitative sensory testing in painful osteoarthritis: a systematic review and meta-analysis. Osteoarthritis Cartilage 2012;20:1075-85 CrossRef Medline

22. Arendt-Nielsen L, Yarnitsky D. Experimental and clinical applications of quantitative sensory testing applied to skin, muscles and viscera. J Pain 2009;10:556-72 CrossRef Medline

23. Bouwense SA, Olesen SS, Drewes AM, et al. Effects of pregabalin on central sensitization in patients with chronic pancreatitis in a randomized, controlled trial. PLoS One 2012;7:e42096 CrossRef Medline

24. O’Neill S, Manniche C, Graven-Nielsen T, et al. Generalized deeptissue hyperalgesia in patients with chronic low-back pain. Eur J Pain 2007;11:415-20 CrossRef Medline

25. Wilder-Smith, OH. Chronic pain and surgery: a review of new insights from sensory testing. J Pain Palliat Care Pharmacother 2011; 25:146-59 CrossRef Medline

26. Erpelding N, Moayedi M, Davis KD. Cortical thickness correlates of pain and temperature sensitivity. Pain 2012;153:1602-09 CrossRef Medline

27. Seminowicz DA, Laferriere AL, Millecamps M, et al. MRI structural brain changes associated with sensory and emotional function in a rat model of long-term neuropathic pain. Neuroimage 2009;47: 1007-14 CrossRef Medline 
28. Hofman A, Darwish Murad S, van Duijn CM, et al. The Rotterdam Study: 2014 objectives and design update. Eur J Epidemiol 2013;28: 889-926 CrossRef Medline

29. Ikram MA, van der Lugt A, Niessen WJ, et al. The Rotterdam Scan Study: design and update up to 2012. Eur J Epidemiol 2011;26:811-24 CrossRef Medline

30. de Boer R, Vrooman HA, van der Lijn F, et al. White matter lesion extension to automatic brain tissue segmentation on MRI. Neuroimage 2009;45:1151-61 CrossRef Medline

31. Vrooman HA, Cocosco CA, van der Lijn F, et al. Multi-spectral brain tissue segmentation using automatically trained k-nearest-neighbor classification. Neuroimage 2007;37:71-81

32. Wolfe F, Smythe HA, Yunus MB, et al. The American College of Rheumatology 1990 Criteria for the Classification of Fibromyalgia. Report of the Multicenter Criteria Committee. Arthritis Rheum 1990;33:160-72 CrossRef Medline

33. Buckalew N, Haut MW, Morrow L, et al. Chronic pain is associated with brain volume loss in older adults: preliminary evidence. Pain Med 2008;9:240-48 CrossRef Medline

34. Burgmer M, Gaubitz M, Konrad C, et al. Decreased gray matter volumes in the cingulo-frontal cortex and the amygdala in patients with fibromyalgia. Psychosom Med 2009;71:566-73 CrossRef Medline

35. Jensen KB, Srinivasan $P$, Spaeth $R$, et al. Overlapping structural and functional brain changes in patients with long-term exposure to fibromyalgia pain. Arthritis Rheum 2013;65:3293-303 CrossRef Medline

36. Kong J, Spaeth RB, Wey HY, et al. S1 is associated with chronic low back pain: a functional and structural MRI study. Mol Pain 2013; 9:43 CrossRef Medline

37. Kuchinad A, Schweinhardt P, Seminowicz DA, et al. Accelerated brain gray matter loss in fibromyalgia patients: premature aging of the brain? J Neurosci 2007;27:4004-07 CrossRef Medline

38. Lutz J, Jäger L, de Quervain D, et al. White and gray matter abnormalities in the brain of patients with fibromyalgia: a diffusion- tensor and volumetric imaging study. Arthritis Rheum 2008;58: 3960-69 CrossRef Medline

39. Rodriguez-Raecke $\mathrm{R}$, Niemeier A, Ihle $\mathrm{K}$, et al. Brain gray matter decrease in chronic pain is the consequence and not the cause of pain. J Neurosci 2009;29:13746-50 CrossRef Medline

40. Schmidt-Wilcke T, Luerding R, Weigand T, et al. Striatal grey matter increase in patients suffering from fibromyalgia-a voxel-based morphometry study. Pain 2007;132(suppl 1):S109-16 CrossRef Medline

41. Seminowicz DA, Wideman TH, Naso L, et al. Effective treatment of chronic low back pain in humans reverses abnormal brain anatomy and function. J Neurosci 2011;31:7540-50 CrossRef Medline

42. Valet M, Gündel H, Sprenger T, et al. Patients with pain disorder show gray-matter loss in pain-processing structures: a voxel-based morphometric study. Psychosom Med 2009;71:49-56 CrossRef Medline

43. Wood PB, Glabus MF, Simpson R, et al. Changes in gray matter density in fibromyalgia: correlation with dopamine metabolism. J Pain 2009;10:609-18 CrossRef Medline

44. Henderson LA, Gandevia SC, Macefield VG. Gender differences in brain activity evoked by muscle and cutaneous pain: a retrospective study of single-trial fMRI data. Neuroimage 2008;39:1867-76 CrossRef Medline

45. Labus JS, Naliboff BN, Fallon J, et al. Sex differences in brain activity during aversive visceral stimulation and its expectation in patients with chronic abdominal pain: a network analysis. Neuroimage 2008; 41:1032-43 CrossRef Medline

46. Lombardo MV, Ashwin E, Auyeung B, et al. Fetal testosterone influences sexually dimorphic gray matter in the human brain. J Neurosci 2012;32:674-80 CrossRef Medline

47. McCarthy MM, Auger AP, Bale TL, et al. The epigenetics of sex differences in the brain. J Neurosci 2009;29:12815-23 CrossRef Medline

48. Peper JS, Koolschijn PC. Sex steroids and the organization of the human brain. J Neurosci 2012;32:6745-46 CrossRef Medline 